\title{
Isotope ratio mass spectrometry in antidoping analysis: The use of endogenous reference compounds
}

\author{
Xavier de la Torre ${ }^{1}$ (D) | Daniel Jardines ${ }^{1}$ | Davide Curcio $^{1}$ | Cristiana Colamonici ${ }^{1}$ । \\ Francesco Botrè ${ }^{1,2}$
}

${ }^{1}$ Laboratorio Antidoping, Federazione Medico Sportiva Italiana, Largo Giulio Onesti 1, 00197 Rome, Italy

${ }^{2}$ Dipartimento di Medicina Sperimentale, "Sapienza" Università di Roma, Viale Regina Elena 324, 00161 Rome, Italy

Correspondence

X. de la Torre, Laboratorio Antidoping, Federazione Medico Sportiva Italiana, Largo Giulio Onesti 1, 00197 Rome, Italy.

Email: xavier.delatorre@gmail.com

Funding information

World Anti-Doping Agency, Grant/Award Number: 17D15XD
Rationale: Isotope ratio mass spectrometry (IRMS) is an analytical technique required by the World Antidoping Agency (WADA) before releasing of an adverse finding for the abuse of pseudoendogenous steroids (i.e. testosterone). For every single individual, the delta ${ }^{13} \mathrm{C}$ values (\%) of the selected target compounds (TCs, i.e. testosterone and/or its precursors/metabolites) are compared with those of endogenous reference compounds (ERCs). The aim of this work is to investigate the individual variation in the delta values of four different commonly used ERCs to establish the maximum acceptable variation, in order to detect potential outliers.

Methods: Routine urine samples collected for antidoping purposes were submitted to IRMS confirmation. After a specific liquid chromatographic purification of the analytes of interest, the final extracts were analyzed by gas chromatography/combustion (GC/C)-IRMS. The selected ERCs monitored were pregnanediol, pregnanetriol, 11keto-etiocholanolone and $11 \beta$-hydroxyandrosterone. The obtained ${ }^{13} \mathrm{C}$ delta values were statistically analyzed to evaluate their inter- and intra-individual distribution.

Results: The delta values of the ERCs studied showed a normal distribution and no major differences among genders were observed. As expected, there are differences depending on the geographical origin of the samples, reflecting different dietary habits and food sources. The intra-individual dispersion, expressed as the standard deviation (SD) of the values of the studied ERCs, did not greatly exceed the instrumental error $(0.5 \%)$, demonstrating the good preservation of the delta values along the metabolic pathway.

Conclusions: For the selected ERCs of non-sporting volunteers and the urinary specimens from more than 1000 sportsmen, we can propose a maximum SD of $0.54 \%$ and range of $1.2 \%$ or for delta ${ }^{13} \mathrm{C}$ values as acceptance criteria to detect potential outliers. These cases can be caused by the external masking effect of the administration of a substance modifying the delta values or outliers due to unforeseen procedural artifacts.

\section{1 | INTRODUCTION}

Isotope ratio mass spectrometry (IRMS) is the technique of choice when carrying out antidoping controls in sports for distinguishing between the synthetic and endogenous (physiological) origin of testosterone in urine samples. In fact, the use of IRMS is mandatory by the World Antidoping Agency (WADA) $)^{1}$ before the release of an adverse analytical finding for the abuse of pseudoendogenous steroids (i.e. testosterone and/or testosterone precursors/ metabolites) included in the WADA prohibited list. ${ }^{2}$

The technique is based on the specific origin of the phytosteroids used by the pharmaceutical industry for the synthesis of steroid hormones (mainly from soy, a C3 plant). ${ }^{3,4}$ This creates a natural isotopic labelling, reducing the $\delta^{13} \mathrm{C}$ values of the synthetic steroids 
(in the -26 to $-33 \%$ range) compared with the human naturally produced steroids that depend mainly on the diet of the individuals (ranging from -18 to $-25 \%$ o). ${ }^{5}$

To make the data evaluation more robust, the delta values of the selected target compounds (TCs, i.e. testosterone and its precursors/metabolites) are compared with those of endogenous reference compounds (ERCs) at higher stages of human metabolism, not influenced by the exogenous administration of pseudoendogenous steroids. Based on population reference ranges, delta-delta limit values $\left(\Delta \delta_{\text {ERC-TC }}\right)$ have been established. ${ }^{1}$

The correct selection of the ERC is of fundamental importance to ensure the reliability of the results. In the past, the use of cholesterol ${ }^{6}$ was proposed, only to be later abandoned because its urinary origin was not well known. Currently, the main compounds used as ERCs originate from progestins (pregnanediol, $\mathrm{PD}^{7}$ ), corticosteroids (11-ketoetiocholanolone, 11-oxo-Etio ${ }^{5}$ ) and other adrenal precursors (5aandrost-16-en-3a-ol, $16-\mathrm{en}^{8}$ and $11 \beta$-hydroxyandrosterone, 11-OH-A ${ }^{9}$ ).

In routine analyses, PD is preferred by the WADA as the primary ERC, and it is only replaced when the signal is suppressed, affected by poor chromatography or by the administration of a precursor, e.g. pregnenolone or progesterone. ${ }^{10,11}$ Thus, the study how the ERCs may be affected, not by the pseudoendogenous androgens but by other steroid precursors (whether or not included in the prohibited list), is relevant since the efficacy of the technique could be impaired.

It has been demonstrated that most of the ERCs used so far may be affected by the exogenous administration of steroidal substances, prohibited or not by the WADA, included in nutritional supplements used by athletes. The administration of adrenosterone ${ }^{12}$ and cortisol $^{13}$ will affect $11 \mathrm{OHA}$ and $11 \mathrm{KE}$. The administration of pregnenolone and progesterone leads to the formation of $\mathrm{PD}^{11,14}$ and to a lesser extent to $16-\mathrm{en},{ }^{10}$ that will have a delta value close to that of the compound in the pharmaceutical/nutritional preparation. Because of this, PD cannot be used as an ERC since its diagnostic capacity is clearly reduced. Two main issues should be addressed: (1) how to determine that the delta value of PD means that it is non-physiological and (2) whether, and if so, how, could alternative ERCs (other than cholesterol), not affected by any steroid precursor, be selected.

In a previous report, Piper et al ${ }^{11}$ demonstrated that pregnanetriol (PT) and pregn-5-ene-3ß,17,20a-triol are not affected by pregnenolone administration. In the present work, we investigate the use of PT as an ERC not affected by exogenous administrations. In addition, we investigate the variation in the delta values of four different commonly used ERCs, with the aim of establishing what is the maximum acceptable variation, to detect potential outliers or compounds not suitable to be used as ERCs in specific cases.

\section{I EXPERIMENTAL}

\section{1 | Procedure for IRMS analysis}

Urine samples were prepared as previously described. ${ }^{15}$ Briefly, $3-12 \mathrm{~mL}$ of urine depending on the concentrations of the compounds of interest previously estimated by GC/MS was submitted to enzymatic hydrolysis (E. coli) followed by liquid-liquid extraction with tert-butyl methyl ether at alkaline $\mathrm{pH}$ (9-10), and the organic phase taken to dryness. The dry residue was reconstituted in a water/methanol mixture and injected into a model 1100 liquid chromatograph (Agilent Technologies SpA, Cernusco sul Naviglio, Italy) equipped with a C18 column (ACE ${ }^{\circ} 25 \mathrm{~cm}, 4.6 \mathrm{~mm}$ and $5 \mu \mathrm{m}$ ) for compound purification. The fractions around the peaks of interest were collected, taken to dryness and combined before their injection into the GC/C-IRMS Delta Advantage system (Thermo Electron, Bremen, Germany) without any derivatization.

\section{2 | Quality control samples}

Along with the urine samples, different certified reference materials and controls were analyzed to verify the stability and accuracy of the GC/C-IRMS analyses. Among them, a negative quality control (NQC) consisting of the pooled urine collected over 3 days from a healthy male and a positive quality control (PQC) consisting of a pooled urine from the same volunteer after the administration of $150 \mathrm{mg}$ of dehydroepiandrosterone (DHEA) (i-Health DHEA, Cronwell, CT, USA) were analyzed in every analytical batch. A certified reference material (USADA CU-041) ${ }^{16}$ was injected at the beginning and end of the sequence to verify the accuracy and any potential drift of the measurements over time. A variation of $\pm 0.5 \%$ 。 was considered acceptable.

\section{3 | Population study}

\subsection{1 | Non-sporting population}

Urine samples collected from Italian Caucasian individuals (22 females and 34 males) who did not participate in sport at a competitive level and who declared that they were not using any drug that might modify the normal excretion of endogenous steroids were collected and kept frozen until analysis. The goal was to verify that the criteria in the TD2016IRMS Technical Document required before an adverse analytical finding for a sample could be declared were not met, thus demonstrating the validity of the procedure that has been developed.

\subsection{2 | Sporting population}

Urine samples from 1094 (974 males and 120 females) athletes submitted to regular antidoping testing were analyzed using the procedure previously described. The samples were selected according to the criteria indicated in the WADA TR2016IRMS Technical Document or when a confirmation was considered necessary by the WADA recognized Athlete Passport Management Unit (APMU, https://www.wada-ama.org/en/resources/athlete-biologicalpassport/td2019apmu).

Statistical analysis of the data was performed with MatLab (MathWorks, Natick, MA, USA). 


\section{3 | RESULTS AND DISCUSSION}

\section{1 | Quality control}

Tables $1 \mathrm{~A}$ and $1 \mathrm{~B}$ report the results of the $\mathrm{QC}$ samples injected in every analytical batch. The SDs are less than $0.5 \%$, showing the good repeatability of the procedure. As can be observed, the ERCs delta values are not altered by the administration of DHEA with overlapping values in the QCN and QCP samples collected from the same individual. Similar data were obtained during the whole period where the project was developed, but with different batches of pooled urine samples. The last batch in use is shown, to demonstrate the repeatability of the data and robustness of the method applied.

\section{2 | Non-sporting samples}

The procedure for the confirmation of pseudoendogenous steroids, currently in use in our laboratory, involves the analysis of five TCs and four ERCs. One of the motivations to do so is that by the correct combination of the LC fractions obtained during the sample purification, it is possible to inject four fractions, with an ERC being included in every fraction. Even in the worst-case scenario this should allow a reliable delta-delta value to be obtained within every single injection, reducing the effect of any potential instrumental variability.

The selected ERCs, 11-OH-A, 11-oxo-Etio, PD and PT, cover the main branches of steroid biosynthesis, including progestins and corticosteroids. Some authors have also proposed the use of 16 -en as an ERC. $^{8}$ In our case, this compound was discarded since it requires a much longer running time for the preliminary LC purification.

Urine samples from 22 females and 34 males who were not practising sport at a competitive level and who declared that they were not using any drug that might modify the normal excretion of endogenous steroids were analyzed. Due to the reduced number of these samples, their analysis as a reference population was intended to verify and confirm that the criteria required in the TD2016IRMS Technical Document to report an adverse analytical finding were not met.

Table 2 shows the statistical data evaluation separated by gender. The means $(\mu)$ of the $\delta_{\text {ERC }}$ values are similar and the differences between groups for the same compound are less than $0.5 \%$. The dispersion of the delta values for 11-OH-A, 11-oxo-Etio and PT in the female group is, however, higher than in males.

The other small difference is shown in Figure 1; although not statistically significant, all the ERCs in female samples had slightly lower delta values.

\section{3 | Athletes' population}

During the last three years (2016 to July 2018), 1094 samples from sports people submitted to official antidoping analyses (120 females) were analyzed by IRMS allowing us to study the behavior of all the ERCs measured in our laboratory. Tables $3 \mathrm{~A}, 3 \mathrm{~B}$ and $3 \mathrm{C}$ present the statistical description of the data for the ERCs, including PT, which is not considered in the WADA Technical Document. Considering

TABLE 1A Negative quality control (NQC) (Period January-July 2018)

\begin{tabular}{|c|c|c|c|c|c|c|c|c|c|}
\hline & \multicolumn{5}{|l|}{$\mathrm{TCs}$} & \multicolumn{4}{|l|}{ ERCs } \\
\hline & A & Etio & $5 a 3 a A$ & $5 b 3 a A$ & $\mathbf{T}$ & $11-\mathrm{OH}-\mathrm{A}$ & 11-oxo-Etio & PD & PT \\
\hline Mean & -23.56 & -24.34 & -24.23 & -23.90 & -24.17 & -23.67 & -23.59 & -23.68 & -23.35 \\
\hline SD & 0.30 & 0.35 & 0.31 & 0.49 & 0.54 & 0.32 & 0.38 & 0.33 & 0.40 \\
\hline Max & -22.92 & -23.60 & -23.73 & -23.24 & -23.17 & -23.00 & -22.39 & -23.06 & -22.45 \\
\hline Min & -24.21 & -25.06 & -25.22 & -25.25 & -25.37 & -24.47 & -24.34 & -24.27 & -24.27 \\
\hline Range & 1.3 & 1.5 & 1.5 & 2.0 & 2.2 & 1.5 & 2.0 & 1.2 & 1.8 \\
\hline $\mathrm{n}$ & 52 & 52 & 52 & 52 & 52 & 52 & 52 & 52 & 52 \\
\hline Mean + 3SD & -22.65 & -23.29 & -23.31 & -22.44 & -22.54 & -22.70 & -22.45 & -22.68 & -22.17 \\
\hline Mean-3SD & -24.46 & -25.38 & -25.14 & -25.37 & -25.80 & -24.64 & -24.73 & -24.67 & -24.54 \\
\hline
\end{tabular}

TABLE 1B Positive quality control (PQC) (Period January-July 2018)

\begin{tabular}{|c|c|c|c|c|c|c|c|c|c|}
\hline & \multicolumn{5}{|l|}{ TCs } & \multicolumn{4}{|l|}{ ERCs } \\
\hline & A & Etio & $5 a 3 a A$ & $5 b 3 a A$ & $\mathbf{T}$ & 11-OH-A & 11-oxo-Etio & PD & PT \\
\hline Mean & -28.82 & -30.33 & -27.76 & -28.43 & -27.58 & -23.72 & -23.51 & -23.95 & -23.59 \\
\hline SD & 0.31 & 0.28 & 0.38 & 0.50 & 0.46 & 0.37 & 0.36 & 0.34 & 0.32 \\
\hline Max & -28.07 & -29.87 & -27.09 & -27.72 & -27.14 & -23.09 & -22.87 & -23.31 & -22.94 \\
\hline Min & -29.26 & -31.07 & -28.83 & -29.93 & -28.93 & -24.80 & -24.29 & -24.83 & -24.37 \\
\hline Range & 1.2 & 1.2 & 1.7 & 2.2 & 1.8 & 1.7 & 1.4 & 1.5 & 1.4 \\
\hline$n$ & 52 & 52 & 52 & 52 & 52 & 52 & 52 & 52 & 52 \\
\hline Mean + 3SD & -27.89 & -29.50 & -26.61 & -26.93 & -26.19 & -22.61 & -22.44 & -22.92 & -22.62 \\
\hline Mean-3SD & -29.75 & -31.16 & -28.90 & -29.94 & -28.97 & -24.84 & -24.59 & -24.97 & -24.56 \\
\hline
\end{tabular}


TABLE 2 Statistical data description of $\delta_{\text {ERC }}$ values (\%o) of non-sports population ( $n=22$ females and $n=34$ males)

\begin{tabular}{|c|c|c|c|c|c|c|c|c|}
\hline \multirow{3}{*}{ 更 } & \multicolumn{4}{|l|}{ Female } & \multicolumn{4}{|l|}{ Male } \\
\hline & $11-\mathrm{OH}-\mathrm{A}$ & 11-oxo-Etio & PD & PT & 11-OH-A & 11-oxo-Etio & PD & PT \\
\hline & -23.04 & -22.74 & -22.82 & -22.66 & -22.75 & -22.45 & -22.66 & -22.56 \\
\hline SD & 0.57 & 0.67 & 0.70 & 0.52 & 0.49 & 0.66 & 0.57 & 0.49 \\
\hline Max & -21.61 & -21.29 & -21.53 & -21.57 & -21.57 & -20.84 & -21.45 & -21.27 \\
\hline$\mu-2^{*} S D$ & -24.18 & -24.09 & -24.22 & -23.69 & -23.74 & -23.78 & -23.80 & -23.54 \\
\hline$\mu+2 * S D$ & -21.89 & -21.39 & -21.41 & -21.63 & -21.76 & -21.13 & -21.51 & -21.57 \\
\hline
\end{tabular}

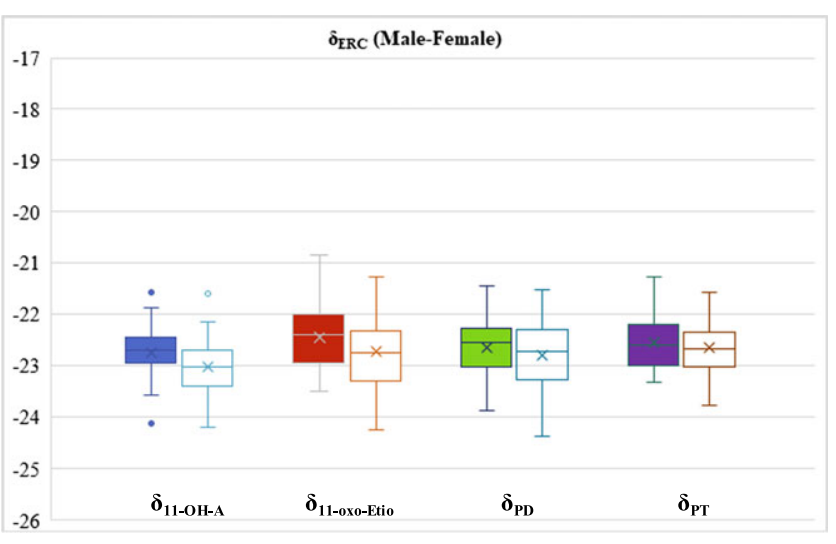

FIGURE 1 Box-plot of $\delta_{\text {ERC }}$ values (\%) of non-sporting population, 34 male samples (filled box) and 22 female samples (open box) [Color figure can be viewed at wileyonlinelibrary.com]

the lower number of female athletes and the gender independence observed for samples from non-sports people, the evaluation of the data was performing by considering the samples as a single group.

The null ERCs in the tables indicate the number of samples where the measurement of some of the delta values was either not possible or not reliable. There is no specific tendency, but this number decreased over the years; 11-oxo-Etio has a low incidence of null cases, while the frequency is higher for PT (see supporting information). There could be multiple causes for the null cases, from potential chromatographic co-elution to too low concentrations or bad chromatographic behavior. The null ERCs are randomly distributed, by the combination of one or two ERCs absent in a sample. In this sense, the three combinations (4, 3 or 2 ERCs present) over the years have a similar distribution (Table 4).

The mean $(\mu)$ of the delta values of the ERCs showed a slight difference among the three years, although this difference was below $0.5 \%$, the commonly accepted instrumental error. Although not statistically significant, the delta values for $11-\mathrm{OH}-\mathrm{A}$ and PD are slightly more negative, while they are more positive for 11-oxo-Etio and PT (see box-plots of the different years' population, Figures 2A-2C).

The standard deviations (SDs) are also almost identical among the different ERCs. The SDs are small, compared with those of a more homogenous population (Table 2) and the fact that the maximum acceptable uncertainty for a repeated measurement of the same sample by WADA is $1 \%$, mainly depending on the origin of the
TABLE 3A Statistical data review of $\delta_{\text {ERC }}$ values (\%o) of 479 (49 female) samples analyzed by IRMS in 2016

\begin{tabular}{lcccc}
\hline $\mathbf{2 0 1 6}$ & 11-OH-A & 11-oxo-Etio & PD & PT \\
\hline $\mathbf{N}$ & 461 & 471 & 451 & 449 \\
\hline Null & 18 & 8 & 28 & 30 \\
\hline $\boldsymbol{\mu}$ & -22.29 & -21.95 & -22.29 & -22.20 \\
\hline Median & -22.38 & -22.07 & -22.44 & -22.25 \\
\hline SD & 1.23 & 1.24 & 1.30 & 1.20 \\
\hline Max & -17.6 & -16.9 & -17.1 & -17.3 \\
\hline Min & -25.5 & -25.4 & -25.3 & -25.1 \\
\hline Range & 7.9 & 8.5 & 8.2 & 7.8 \\
\hline $\boldsymbol{\mu - 2}$ SD & -24.75 & -24.43 & -24.88 & -24.60 \\
\hline $\boldsymbol{\mu + 2}$ 2SD & -19.83 & -19.46 & -19.69 & -19.79 \\
\hline
\end{tabular}

TABLE 3B Statistical data review of $\delta_{\text {ERC }}$ values (\%o) of 359 (32 female) samples analyzed by IRMS in 2017

\begin{tabular}{lcccc}
\hline 2017 & $11-\mathrm{OH}-\mathrm{A}$ & 11-oxo-Etio & PD & PT \\
\hline $\mathbf{N}$ & 352 & 357 & 350 & 347 \\
\hline Null & 7 & 2 & 9 & 12 \\
\hline $\boldsymbol{\mu}$ & -22.31 & -22.21 & -22.49 & -22.22 \\
\hline Median & -22.37 & -22.29 & -22.59 & -22.25 \\
\hline SD & 1.01 & 1.01 & 1.04 & 1.00 \\
\hline Max & -16.7 & -17.0 & -16.7 & -17.1 \\
\hline Min & -25.1 & -25.0 & -24.9 & -24.7 \\
\hline Range & 8.5 & 8.0 & 8.2 & 7.6 \\
\hline $\boldsymbol{\mu - 2}$ SD & -24.32 & -24.22 & -24.56 & -24.22 \\
\hline $\boldsymbol{\mu + 2}$-SD & -20.30 & -20.19 & -20.41 & -20.22 \\
\hline
\end{tabular}

TABLE 3C Statistical data review of $\delta_{\text {ERC }}$ values (\%) of 256 (39 female) samples analyzed by IRMS in January-July 2018

\begin{tabular}{|lcccc|}
\hline 2018 & $11-O H-A$ & 11-oxo-Etio & PD & PT \\
\hline $\mathbf{N}$ & 254 & 253 & 253 & 241 \\
\hline Null & 2 & 3 & 3 & 15 \\
\hline$\mu$ & -22.79 & -22.56 & -22.75 & -22.57 \\
\hline Median & -22.74 & -22.65 & -22.71 & -22.57 \\
\hline SD & 0.93 & 0.94 & 0.93 & 0.87 \\
\hline Max & -18.9 & -18.9 & -18.6 & -19.2 \\
\hline Min & -24.9 & -25.6 & -25.4 & -25.0 \\
\hline Range & 6.0 & 6.7 & 6.8 & 5.8 \\
\hline$\mu-2 * S D$ & -24.64 & -24.43 & -24.61 & -24.31 \\
\hline$\mu+2 * S D$ & -20.94 & -20.69 & -20.89 & -20.82 \\
\hline
\end{tabular}


TABLE 4 Distribution of the number of ERCs measured by sample

\begin{tabular}{|c|c|c|c|c|c|c|}
\hline \multirow[b]{2}{*}{ \#ERC } & \multicolumn{2}{|c|}{2016} & \multicolumn{2}{|c|}{2017} & \multicolumn{2}{|c|}{2018} \\
\hline & $\bar{N}$ & $\%$ & $\bar{N}$ & $\%$ & $\bar{N}$ & $\%$ \\
\hline 4 & 404 & 84.3 & 333 & 92.8 & 234 & 91.4 \\
\hline 3 & 66 & 13.8 & 22 & 6.1 & 21 & 8.2 \\
\hline 2 & 9 & 1.9 & 4 & 1.1 & 1 & 0.4 \\
\hline Total samples & 479 & & 359 & & 256 & \\
\hline
\end{tabular}

(A)

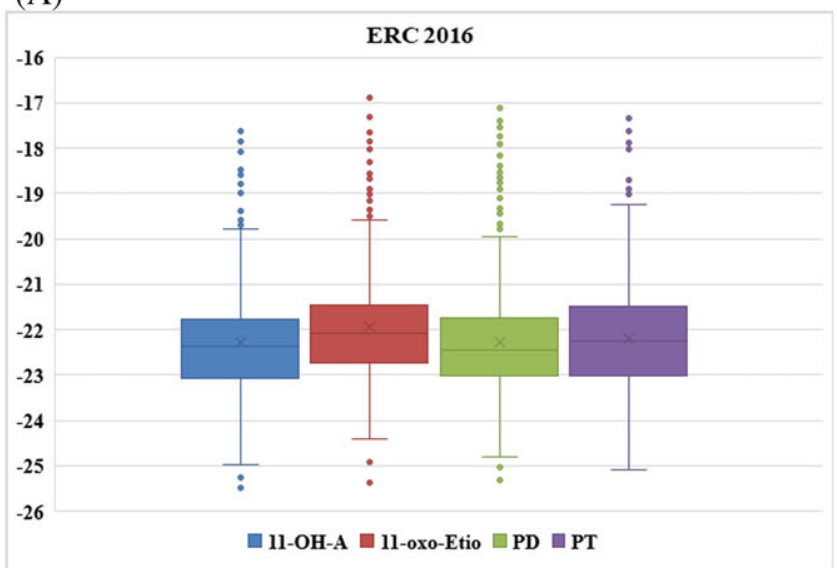

(B)

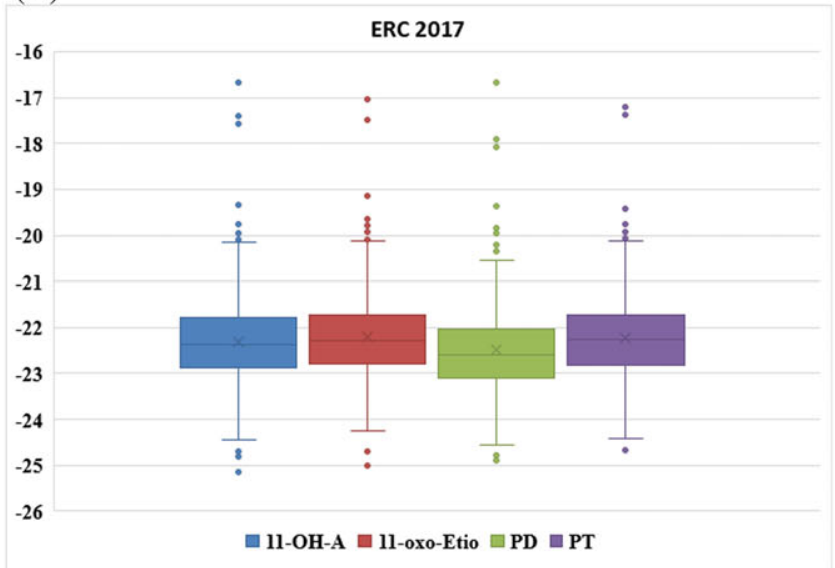

(C)

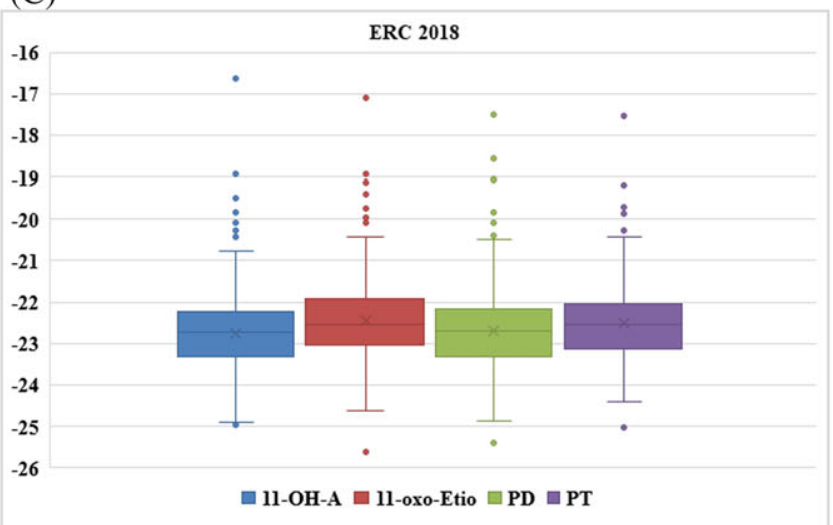

FIGURE 2 Box-plots of $\delta_{\text {ERC }}$ values (\%) obtained A, in the year 2016; B, in the year 2017; and C, in the year 2018 [Color figure can be viewed at wileyonlinelibrary.com] athletic population considered in the dataset. During 2016, 43 samples out of 479 (9\%) analyzed were not from Italy but from other parts of the world (China, South Africa or Qatar), with consequently more dispersion in the data. In fact, samples from these other regions (Figure 2A) behave as outliers (outside the reference ranges defined in the box plot) compared with the Italian athletes' population. These differences could be considered as being mainly linked to different diets. This effect was less marked in the other two years due to the
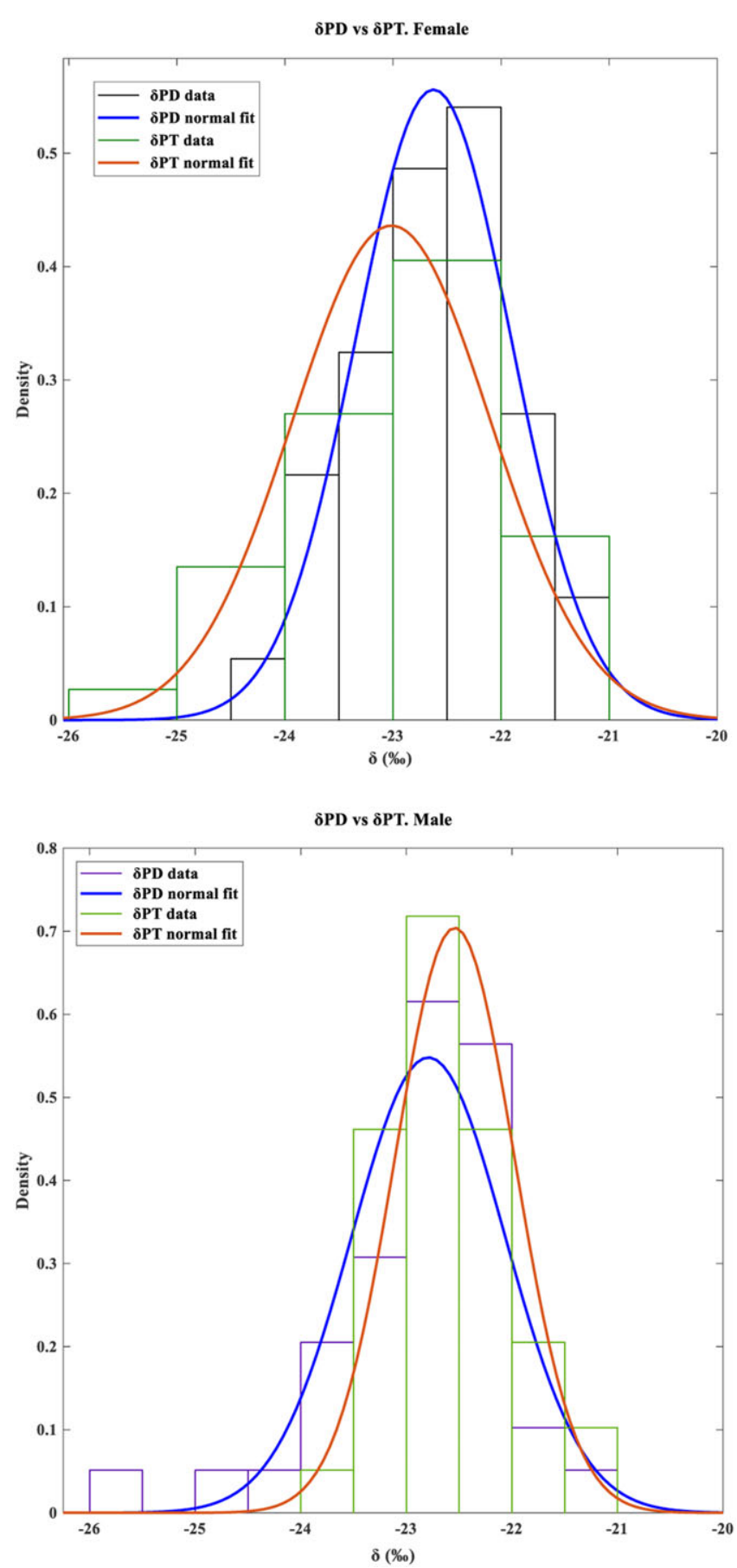

FIGURE 3 Data and curve distribution fit of female and male nonathletic population for $\delta_{\mathrm{PD}}$ and $\delta_{\mathrm{PT}}$ values [Color figure can be viewed at wileyonlinelibrary.com] 
samples being from a more homogeneous local population. In 2016 the non-European population of the samples was estimated as being about $15 \%$, but this was reduced to $4 \%$ in 2017 , and was almost negligible in 2018.

Compared with the non-athletic population, the results follow the male pattern; the proportion of samples in the dataset from males is always higher (89.9\% in 2016, 91.3\% in 2017 and $82.6 \%$ in 2018). As a consequence, the influence of the male pattern is predominant.

\section{4 | Use of pregnanetriol (PT) as ERC}

As previously stated, the main characteristics of an endogenous compound to be used as an ERC are: stability, the values not being affected by the exogenous administration of other compounds (prohibited or not), and the fact that they belong to the same metabolic pathway as the target compounds but at higher stages of the biosynthetic pathway. Of the four ERCs considered in this work, three of them (11-OH-A, 11-oxo-Etio and PD) can be affected by the external administrations of other compounds, invalidating to some extent their use or at least reducing the sensitivity of the method. PT is not affected by any of the previous indicated administrations and therefore it could be considered a more robust metabolic ERC. The only drawback is that underivatized PT has a less favorable chromatographic performance.

To prove the validity of PT as an ERC, a more detailed comparison with $\mathrm{PD}$ (the preferred ERC) is presented. Histograms representing the delta values of PD and PT data and the density curve fit for a normal distribution are presented in Figure 3 for the non-athletic population. Both sets of ERC data are normally distributed. The $\delta_{P D}$ values have almost the same position and shape for males and females, while for the $\delta_{\text {PT }}$ values there is a shift of $0.5 \%$ o between the two populations, being more negative for females, although the differences are not significant. In addition, the $\delta_{\mathrm{PT}}$ value has more dispersion in females than in males (Table 2).

Consequently, the $\Delta \delta_{\text {ERC-TC }}$ values for the female and male populations are also very similar for both ERCs, with some minor differences in the dispersion of the data (see box plots in Figure 4). In almost all the cases, the female group has more dispersion, except for the $\Delta_{\delta E R C-T}$, which is slightly larger for the male group. Another characteristic found in $\Delta \delta_{\text {PT-TC }}$ is that the limits for the outliers in all the TC combinations are less than $3 \%$, in agreement with the proposed limits indicated in the TDTIRMS Technical Document, demonstrating also that no "false positive" cases are observed.

After showing that there are no differences between PD and PT at the population level, in a previous report ${ }^{17}$ we demonstrated that the use of PD or PT did not change the detection capacity of the procedure and that after a DHEA administration the same final evaluation was reached using either of the two ERCs.

TABLE 5 Statistical analysis of the ERC variation for non-sports population expressed as the SD (\%) and range (\%) of the data of the single individuals

\begin{tabular}{|c|c|c|c|c|c|c|}
\hline & Fema & & Male & & All & \\
\hline & $\overline{S D}$ & Range & $\overline{S D}$ & Range & SD & Range \\
\hline$\mu$ & 0.23 & 0.58 & 0.28 & 0.73 & 0.26 & 0.67 \\
\hline Median & 0.21 & 0.51 & 0.28 & 0.75 & 0.28 & 0.70 \\
\hline SD & 0.14 & 0.35 & 0.12 & 0.32 & 0.13 & 0.34 \\
\hline Max & 0.52 & 1.32 & 0.55 & 1.44 & 0.60 & 1.4 \\
\hline Min & 0.07 & 0.16 & 0.08 & 0.16 & 0.10 & 0.2 \\
\hline Range & 0.45 & 1.16 & 0.48 & 1.28 & 0.50 & 1.3 \\
\hline$\mu+2 * S D$ & 0.50 & 1.29 & 0.52 & 1.37 & 0.52 & 1.35 \\
\hline Percentil & & & & & & \\
\hline $2.5 \%$ & 0.07 & 0.16 & 0.08 & 0.21 & 0.07 & 0.16 \\
\hline $25.0 \%$ & 0.11 & 0.27 & 0.18 & 0.50 & 0.15 & 0.38 \\
\hline $50.0 \%$ & 0.21 & 0.51 & 0.28 & 0.75 & 0.28 & 0.70 \\
\hline $75.0 \%$ & 0.33 & 0.87 & 0.35 & 0.90 & 0.34 & 0.89 \\
\hline $95.0 \%$ & 0.49 & 1.27 & 0.48 & 1.26 & 0.50 & 1.30 \\
\hline $97.5 \%$ & 0.51 & 1.30 & 0.54 & 1.41 & 0.53 & 1.37 \\
\hline
\end{tabular}
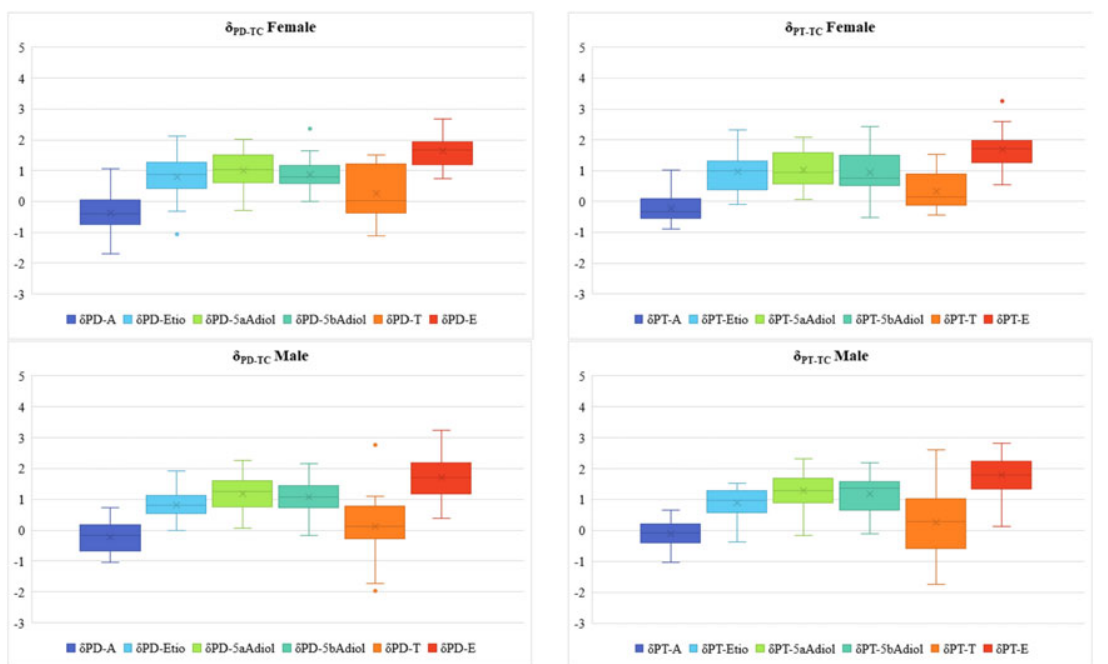

FIGURE 4 Box-plots of female and male population of $\Delta \delta_{\text {ERC-TC }}$ values for the ERCs PD and PT [Color figure can be viewed at wileyonlinelibrary. com] 


\subsection{How many ERCs are needed?}

The use of a unique ERC poses the problem of having only a single reference to estimate the delta-delta value. Since this is a relative value, one should have some reasonable certainty that the ERC value does belong to the endogenous biosynthesis of the individual. In a global sport world, the use of the local population of the laboratory to establish the "normal" range of values is a correct approach, although with some limitations. Since the analyses are performed blind, without knowing the athlete's identity, ethnicity or diet regimen, the individual may not necessarily belong to the "normal" population of the laboratory. The addition of a second ERC, if in agreement with the first one, would strengthen the first value obtained. In the opposite case and having two ERCs that can be affected, which is the correct one? One may consider adding a third and/or fourth ERC in order to have a more global picture of the isotopic signature of the individual. When multiple ERCs are used, and to avoid cherry-picking, criteria to accept or reject values should

TABLE 6 Statistical analysis of the ERC variation for sports population expressed as the SD (\%) and range (\%o) of the data of the single individuals

\begin{tabular}{|c|c|c|c|c|c|c|}
\hline & \multicolumn{2}{|l|}{2016} & \multicolumn{2}{|l|}{2017} & \multicolumn{2}{|c|}{2018} \\
\hline & SD & Range & SD & Range & SD & Range \\
\hline$\mu$ & 0.40 & 0.85 & 0.34 & 0.75 & 0.36 & 0.80 \\
\hline Median & 0.37 & 0.80 & 0.32 & 0.72 & 0.34 & 0.77 \\
\hline SD & 0.20 & 0.42 & 0.17 & 0.37 & 0.19 & 0.43 \\
\hline Max & 1.50 & 2.90 & 1.50 & 3.20 & 1.40 & 3.37 \\
\hline Min & 0.03 & 0.07 & 0.01 & 0.02 & 0.06 & 0.13 \\
\hline Range & 1.42 & 2.80 & 1.49 & 3.23 & 1.35 & 3.23 \\
\hline$\mu+2^{*} \mathrm{SD}$ & 0.79 & 1.69 & 0.67 & 1.50 & 0.74 & 1.63 \\
\hline \multicolumn{7}{|l|}{ Percentile } \\
\hline $2.5 \%$ & 0.10 & 0.22 & 0.07 & 0.15 & 0.12 & 0.28 \\
\hline $25.0 \%$ & 0.25 & 0.54 & 0.22 & 0.48 & 0.23 & 0.49 \\
\hline $50.0 \%$ & 0.36 & 0.78 & 0.32 & 0.72 & 0.34 & 0.78 \\
\hline $75.0 \%$ & 0.50 & 1.09 & 0.44 & 0.97 & 0.43 & 0.99 \\
\hline $95.0 \%$ & 0.73 & 1.67 & 0.67 & 1.48 & 0.72 & 1.49 \\
\hline $97.5 \%$ & 0.90 & 1.86 & 0.67 & 1.48 & 0.82 & 1.67 \\
\hline
\end{tabular}

be established. Although there is a small isotopic fractionation along the steroids' metabolic pathway, good agreement among them is usually observed for every individual. One of the goals of this work is to evaluate what is the maximum variability expected when multiple ERCs are monitored. This should allow those ERCs affected by external administrations or unforeseen procedure artifacts to be discarded, improving the overall data evaluation.

The variation in the four monitored ERCs, expressed as the SD and maximum-minimum range, has been calculated for all the non-sports individuals and the dispersion evaluated (Table 2). Considering the $95 \%$ percentile of the distribution, a maximum SD of $0.5 \%$ and a range of $1.3 \%$ could be used to detect outliers (Table 5). Sports samples presented different although close values (Table 6) but cannot be used to establish the criterion since the presence of outliers due to external administrations of substances cannot be excluded, as demonstrated below. Considering the procedural error $( \pm 0.5 \%$ ) and the maximum uncertainty of the method accepted by the WADA $\left(U_{C_{-} \text {Max }}=2 \%\right.$ with $\left.k=2\right)$, this demonstrates the very high agreement of the values. In $98.8 \%$ of the cases, the proposed criterion can be applied since, only in $1.2 \%$ of the cases, were only 2 ERCs available.

The application of this criterion to the routine samples analyzed in recent years led to the detection of 111 outliers (10\% of the samples). This does not mean that a conclusion could not be reached in $10 \%$ of the cases, but instead that $10 \%$ of samples presented one ERC that behaved abnormally compared with the expected variability. The abnormal cases can be classified as those where the SD and range were higher than the proposed limits for one ERC (74\%), and those where the four ERCs are divided into two consistent subgroups or show disperse values without any pattern (26\%).

There are clear outliers that can be classified as resulting from cortisol administration ( $n=15$ ), pregnenolone or progesterone administration $(n=23)$ or procedure interferences $(n=12)$. Examples illustrating some of the conditions discussed are presented in Table 7.

The elimination of the detected outliers based on the proposed criteria, and recalculation of the $95 \%$ percentile of the athletes' population, led to a SD of $0.54 \%$ and a range of $1.20 \%$. These new values are in excellent agreement with the proposed criteria based on the non-sport population.

TABLE 7 Values of $\delta_{\text {ERC }}(\% \circ)$ for different cases, their SD values (\%) and range (\%o), outliers indicated in bold or italics

\begin{tabular}{|c|c|c|c|c|c|c|c|c|}
\hline Cases & $\delta_{11-\mathrm{OH}-\mathrm{A}}$ & $\delta_{11 \text {-oxo-Etio }}$ & $\delta_{\mathrm{PD}}$ & $\delta_{\mathrm{PT}}$ & $\mu$ & SD_ERC & $\begin{array}{l}\text { Range_ERC } \\
\text { |max-min| }\end{array}$ & Reason* \\
\hline $\begin{array}{l}\# 1 \\
\# 2\end{array}$ & $\begin{array}{l}-23.18 \\
-25.41\end{array}$ & $\begin{array}{l}-23.04 \\
-24.91\end{array}$ & $\begin{array}{l}-23.87 \\
-25.23\end{array}$ & $\begin{array}{l}-22.97 \\
-25.10\end{array}$ & $\begin{array}{l}-23.27 \\
-25.16\end{array}$ & $\begin{array}{l}0.41 \\
0.21\end{array}$ & $\begin{array}{l}0.90 \\
0.50\end{array}$ & Normal $^{* *}$ \\
\hline$\# 4$ & -22.41 & -22.67 & -22.32 & -25.04 & -23.11 & 1.30 & 2.72 & Chromatographic issue \\
\hline \# 6 & -21.97 & -23.14 & -23.64 & -23.63 & -23.09 & 0.78 & 1.66 & $\begin{array}{l}\text { Sample preparation isotopic } \\
\text { Fractionation }\end{array}$ \\
\hline $\begin{array}{l}\# 7 \\
\# 8\end{array}$ & $\begin{array}{l}-23.20 \\
-23.76\end{array}$ & $\begin{array}{l}-23.20 \\
-21.98\end{array}$ & $\begin{array}{l}-21.77 \\
-22.76\end{array}$ & $\begin{array}{l}-21.47 \\
-24.09\end{array}$ & $\begin{array}{l}-22.41 \\
-23.15\end{array}$ & $\begin{array}{l}0.92 \\
0.96\end{array}$ & $\begin{array}{l}1.74 \\
2.11\end{array}$ & $\begin{array}{l}\text { The ERC are distributed in two } \\
\text { homogenous groups }\end{array}$ \\
\hline
\end{tabular}

*Potential explanation for the data obtained.

** Values can be positioned in any place of the normal distribution. 


\section{6 \\ WILEY}

\section{4 | CONCLUSIONS}

The characteristics of the four endogenous steroids used as ERCs in our laboratory for the detection of pseudoendogenous steroids in antidoping analysis have been presented. All of them present similar characteristics and can be used for the scope of the analyses although PD is the preferred ERC as established in the WADA technical document.

No alteration in PT values has been demonstrated so far by the external administration of prohibited or licit substance in sports, making PT potentially a more robust ERC.

When multiple ERCs are used, the evaluation of the variability among them can be used to detect outliers that originate from an external masking effect of the administration of a substance modifying the delta value, or outliers due to unforeseen procedural artefacts. A maximum SD of $0.54 \%$ and range of $1.20 \%$ are proposed as acceptance criteria to detect such circumstances.

The stability of the delta values of the pseudoendogenous steroids, including the ERC necessary for their evaluation, could also be assessed if an evaluation of the delta values was made longitudinally as part of a module of the Athlete Biological Passport (ABP) as we suggested recently. ${ }^{18}$

\section{ACKNOWLEDGEMENT}

The authors thank the World Antidoping Agency (WADA) (Grant No. 17D15XD) for financial support.

\section{ORCID}

Xavier de la Torre (1) https://orcid.org/0000-0001-8037-6750

\section{REFERENCES}

1. WADA. TD2016 IRMS-detection of synthetic forms of endogenous anabolic androgenic steroids by GC-C-IRMS. 2016. Available: https:// wada-main-prod.s3.amazonaws.com/resources/files/wadatd2016irms-detection_synthetic_forms_eaas_by_irms-en.pdf

2. WADA. The World Anti-Doping Code - The 2018 Prohibited List International Standard. 2018. Available: https://www.wada-ama.org/ sites/default/files/prohibited_list_2018_en.pdf

3. Smith BN, Epstein S. Two categories of $\mathrm{c} / \mathrm{c}$ ratios for higher plants. Plant Physiol. 1971;47(3):380-384.

4. O'Leary MH. Carbon isotope fractionation in plants. Phytochemistry. 1981;20(4):553-567.

5. Cawley AT, Trout GJ, Kazlauskas R, Howe CJ, George AV. Carbon isotope ratio ([delta]13C) values of urinary steroids for doping control in sport. Steroids. 2009;74(3):379-392.

6. Becchi M, Aguilera R, Farizon Y, Flament M-M, Casabianca H, James $P$. Gas chromatography/combustion/isotope-ratio mass spectrometry analysis of urinary steroids to detect misuse of testosterone in sport. Rapid Commun Mass Spectrom. 1994;8(4):304-308.
7. Shackleton CHL, Phillips A, Chang T, Li Y. Confirming testosterone administration by isotope ratio mass spectrometric analysis of urinary androstanediols. Steroids. 1997;62(4):379-387.

8. Saudan C, Baume N, Mangin P, Saigy M. Urinary analysis of 16(5a)androsten-3a-ol by gas chromatography/combustion/isotope ratio mass spectrometry: Implications in anti-doping analysis. J Chromatogr B. 2004;810(1):157-164.

9. Flenker U, Güntner U, Schänzer W. $\delta^{13} \mathrm{C}$-values of endogenous urinary steroids. Steroids. 2008;73(4):408-416.

10. Saudan C, Desmarchelier A, Sottas P-E, Mangin P, Saugy M. Urinary marker of oral pregnenolone administration. Steroids. 2005;70(3): 179-183.

11. Piper T, Schlug C, Mareck U, Schänzer W. Investigations on changes in ${ }^{13} \mathrm{C} /{ }^{12} \mathrm{C}$ ratios of endogenous urinary steroids after pregnenolone administration. Drug Test Anal. 2011;3(5):283-290.

12. Brooker L, Parr MK, Cawley A, et al. Development of criteria for the detection of adrenosterone administration by gas chromatographymass spectrometry and gas chromatography-combustion-isotope ratio mass spectrometry for doping control. Drug Test Anal. 2009;1(11-12):587-595.

13. de la Torre $X$, Curcio D, Colamonici $C$, Molaioni F, Cilia M, Botrè F. Development and validation of a GC-C-IRMS method for the confirmation analysis of pseudo-endogenous glucocorticoids in doping control. Drug Test Anal. 2015;7(11-12):1071-1078.

14. Wang J, Yang R, Yang W, Liu X, Xing Y. Impact of progesterone administration on doping test of endogenous steroids. Anal Bioanal Chem. 2014;406(24):6061-6067.

15. de la Torre X, Colamonici C, Curcio D, Molaioni F, Botrè F. A comprehensive procedure based on gas chromatography-isotope ratio mass spectrometry following high performance liquid chromatography purification for the analysis of underivatized testosterone and its analogues in human urine. Anal Chim Acta. 2012;756:23-29.

16. Zhang Y, Tobias HJ, Brenna JT. Steroid isotopic standards for gas chromatography-combustion isotope ratio mass spectrometry (GCC IRMS). Steroids. 2009;74(3):369-378.

17. de la Torre $X$, Colamonici C, Curcio D, Botrè F. Fast IRMS screening of pseudoendogenous steroids in doping analyses. Drug Test Anal. 2017;9(11-12):1804-1812.

18. Jardines D, Botrè F, Colamonici C, Curcio D, Procida G, de la Torre X. Longitudinal evaluation of the isotope ratio mass spectrometric data: Towards the 'isotopic module' of the athlete biological passport? Drug Test Anal. 2016;8(11-12):1212-1221. https://doi.org/10.1002/ dta.2118

\section{SUPPORTING INFORMATION}

Additional supporting information may be found online in the Supporting Information section at the end of the article.

How to cite this article: de la Torre X, Jardines D, Curcio D, Colamonici $\mathrm{C}$, Botrè $\mathrm{F}$. Isotope ratio mass spectrometry in antidoping analysis: The use of endogenous reference compounds. Rapid Commun Mass Spectrom. 2019;33:579-586. https://doi.org/10.1002/rcm.8377 